\title{
Impact of Different Suturing Techniques on Visual Outcomes in Penetrating Keratoplasty
}

\section{Ahmed Raouf, Sameh Saleh, Maha Othman, Eman El-Hifny, Ahmed Ismail}

Mansoura Ophthalmic Center, Faculty of Medicine, Mansoura University, Mansoura, Egypt.

Corresponding author: Dr. Ahmed Raouf, Mansoura Ophthalmic Center, Faculty of Medicine, Mansoura University, Mansoura, Egypt. Tel: 00201005290615; Email: ahmedraouf81@gmail.com

Received: 18-8-2021, Accepted: 30-8-2021, Published online:16-9-2021

EJO(MOC) 2021;3:161-167.

Running title: Suturing technique comparison in penetrating keratoplasty

\section{Abstract}

Purpose: This current study was conducted to investigate the influence of the variable techniques available for corneal suturing on visual outcomes in penetrating keratoplasty (PKP).

Methods: In this prospective study 40 cases underwent PKP which were divided according to the technique of suturing into 2 groups each of 20 patients; first group that underwent continuous suturing and the second group underwent interrupted suturing and they were followed up along 1 year postoperative for best corrected visual acuity (BCVA) and both topographic \& refractive astigmatism.

Result: The results of the study showed comparable improvement between the two techniques regarding the BCVA, refractive astigmatism and topographic astigmatism along the 12 months of follow-up. The need for suture manipulation was higher in the cases underwent interrupted suturing.

Conclusion: there were no significant visual or refractive differences between patients operated with continuous $\&$ interrupted suturing techniques though the patients of the interrupted technique needs more suture manipulation for favorable outcomes than that needed in continuous technique patients.

\section{Introduction}

The acuity of vision following a fruitful PKP is based on the clarity of the graft and residual post-operative error of refraction, especially if it yields astigmatism. High irregular astigmatism is usually found following PKP with subsequent difficulties in visual recovery, although the cornea is clear. Fifteen to thirty percent of patients undergoing PKP may develop postoperative astigmatism greater than 5 diopters ${ }^{1,2, \& 3}$.

Following PKP the astigmatic component of refraction depends on a lot of factors as the difference in size between the recipient bed $\&$ the corneal button, uneven position of the recipient bed $\&$ donor button, diameter of the donor button and type of preoperative corneal pathology (corneal scar or corneal dystrophy for example), wound configuration abnormality, and the suture technique used ${ }^{4,5, \& 6}$.

Two suturing techniques are usually adopted in PKP surgery:

1. Continuous (Single \& double running techniques).
2. Interrupted technique. A lot of studies concluded that the interrupted technique produces more astigmatic error when compared to the other two techniques ${ }^{7}$.

Still the resultant outcomes following PKP adopting any of the two suturing techniques described above regarding which of them is better is a highly debatable issue. There are different conclusions and this discrepancy came from the variability in the follow up periods in various studies \& the timing of suture removal in each study. These results favored a certain technique over the other or left the different techniques comparable in results ${ }^{8,9,10}$.

Efficient rehabilitation of vision requires precise detection of the tight sutures (interrupted technique). Keratometry \& refractometry can help in determination of the suture to be taken off, although they may be misleading in cases of irregular astigmatism. Computerized corneal topography demonstrates the change in corneal power precisely along the whole optical zone \& allows determination of steepest 
meridians which are attributed to the astigmatic suture in particular $^{11,12}$.

This study aims at comparing the effects of two different suturing techniques, both interrupted and continuous techniques on postoperative refraction especially astigmatic error after penetrating keratoplasty after completing a year of postoperative follow up and visual rehabilitation.

\section{Materials and methods:}

This prospective study was performed on patients who underwent PKP in Mansoura ophthalmic center from 2014 to 2018 by one surgeon (Ahmed Mostafa M.D).

All the protocols of our current study were concordant with the tenets of the Declaration of Helsinki and informed consent was obtained from the included subjects. Our obtained IRB code was MD/75. Patients included in this study were chosen from patients attending Mansoura Ophthalmic Centre and complaining from any pathology requiring PKP as dense leukoma or advanced keratoconus.

A minimum visual acuity of perception of hand motion or better in the eye to be operated was a must $\&$ measurement of the BCVA was by standard Snellen's chart. Slit-lamp examination was done to assess the presence or absence of apical corneal opacity, cataract, limbal vascularization \& intact recipient corneal periphery required for convenient donor-receptor interface. IOP was measured by Goldmann's applanation tonometry. Dilated fundus examination was done if no opacities opposing visualization were present. B-scan ultrasonography was done for vitreo-retinal evaluation. Pentacam was done to measure corneal pachymetry at $8 \mathrm{~mm}$ and thinnest location. Good retinal function assurance was preoperatively clarified by electroretinography (ERG) and electrooculogram (EOG).

Patients were randomly assigned to two suturing techniques; continuous and interrupted techniques. Patients with posterior segment affection, lid abnormalities (e.g. lagophthalmos), dry eye, active keratitis, and with postoperative unclear grafts after more than one month were excluded. The patients were followed up at 1 month, 3 months, 6 months, 9 months, and 12 months postoperative. Penetrating keratoplasty was performed by a standard technique using a Hessburg-Barron trephine (JedMed Instrument Co., St. Louis, MO, U.S.A.). For the interrupted suture group, 16 bites were placed with 10-0 nylon. Eye patches were replaced in the first day and patching with eye shield was continued for one week.

All eyes initially received topical antibiotic drops (moxifloxacin $\mathrm{HCl}$ ophthalmic solution, 0.5\%) five times a day, for three weeks. Topical steroid (prednisolone acetate eye drops 1\%) was applied hourly in the first 3 days then 5 to 6 times a day and was subsequently tapered according to the clinical response. Then shift to topical antibiotic-steroid combination (tobramycin - dexamethasone) was done with gradual tapering over 6 months. Topical lubricants were used, if necessary.

Selective removal of interrupted nylon sutures along the steepest meridian was performed, if associated with greater than 5 diopters of astigmatism in that meridian, starting two months after surgery, until the resultant astigmatism reached 3.0 diopters or less. For the single running suture group, a 100nylon running suture with 16 to 24 bites was used with the torque mode, and the sutures were in through the follow-up 12 months duration. Selective suture removal was performed in cases of loose sutures, sutures causing repeated inflammation and vascularization and for tight sutures (judged by refraction, keratometry \& topography) as well.

A minimal suture stay-time of 2 months postoperatively and with close follow-up for any post suture removal wound gaping. The adjacent sutures for that selectively removed are kept for a minimum of 6 months and non-adjacent sutures could be removed at a minimum of 4 weeks after removal of the preceding one. Suture manipulation was done for readjustment in the continuous sutures group after 1 month by tension readjustment \& was also based on refraction, keratometry \& topography. When a small amount of astigmatism is achieved through suture manipulation, the sutures are left in as long as possible, until they fray or break.

\section{Statistical analysis:}

The study was performed at $95 \%$ level of significance and power of $80 \%$. The collected data were coded, processed and analyzed using the SPSS (Statistical Package for Social Sciences) version 22 for Windows ${ }^{\circledR}$ (SPSS Inc, Chicago, IL, USA). Qualitative data was presented as number (frequency) and Percent. Comparison between groups was done by ChiSquare test $\left(x^{2}\right)$. Quantitative data was tested for normality by Kolmogorov-Smirnov test. Data was presented as mean \pm SD. 
Normally distributed quantitative data within two groups was compared by Student t-test. Abnormally distributed quantitative data within two groups was compared by Mann Whitney U test. Comparison between quantitative data at more than two time points was conducted by repeated measures ANOVA. Comparison between each two time points was conducted by paired samples t-test (parametric data) or Wilixon Signed Rank test (nonparametric data). Significance test results are quoted as two-tailed probabilities. For all the above mentioned tests, the level of significance was tested, expressed as the probability of (p-value) and the results were explained as following: non-significant if the $p$ value is $>0.05$, significant if the $p$ value is $\leq 0.05$, \&highly significant if the $p$ value $<0.001$.

\section{Results}

During the period of time covered by this study (2014 to 2018), surgery was performed on 40 patients with different corneal pathologies. 20 eyes of 20 patients underwent PKP with continuous suturing technique, while 20 eyes of 20 patients underwent PKP with 16 interrupted sutures technique.

The mean age of the cases in the continuous suturing group was $28.10 \pm 6.81$ years while in the interrupted suturing group the mean age was $38.45 \pm 12.78$ years with statistically significant difference between the two groups and this difference is due to the randomized selection of the cases and is of no impact on the outcome in each group. The majority of cases in the two study groups were females $(75 \%$ and $70 \%$ in the continuous suturing and interrupted suturing groups respectively).

The cases within the two study groups showed no statistically significant difference in the mean refractive and topographic astigmatism in preoperative, 1, 3, 6 \& 12 months postoperatively. On the other hand, there was a statistically significant difference along the duration of follow up in the cases within the two study groups and the mean refractive and topographic astigmatism preoperatively $(\mathrm{p} \leq 0.001)$. These data are illustrated in tables $1 \& 2$.

Table (1): Assessment of refractive astigmatism along the study duration in the two study groups

\begin{tabular}{|c|c|c|c|}
\hline Time & $\begin{array}{c}\text { Continuous } \\
\text { suturing } \\
n=20\end{array}$ & $\begin{array}{c}\text { Interrupted } \\
\text { suturing } \\
n=20\end{array}$ & $\begin{array}{c}\text { Test of } \\
\text { significance }\end{array}$ \\
\hline 1 month postoperative & $4.31 \pm 1.33$ & $4.68 \pm 2.56$ & $\begin{array}{c}z=-0.562 \\
P=0.577\end{array}$ \\
\hline 3 months postoperative & $3.96 \pm 1.24$ & $4.75 \pm 2.67$ & $\begin{array}{c}z=-1.197 \\
P=0.239\end{array}$ \\
\hline 6 months postoperative & $3.65 \pm 1.17$ & $4.70 \pm 2.08$ & $\begin{array}{c}z=-1.971 \\
P=0.056\end{array}$ \\
\hline 1 year postoperative & $3.31 \pm 1.03$ & $3.61 \pm 1.89$ & $\begin{array}{c}z=-0.625 \\
P=0.536\end{array}$ \\
\hline Overall significance & $\begin{array}{l}F=56.733 \\
P<\mathbf{0 . 0 0 1 *}\end{array}$ & $\begin{array}{l}F=26.043 \\
P<\mathbf{0 . 0 0 1 *}\end{array}$ & \\
\hline
\end{tabular}

P: probability.

Continuous data expressed as mean $\pm \mathrm{SD}$

z: Mann Whitney U-test

F: repeated measures $A N O V A$

*: significant value $<0.05$ 
Impact of Different Suturing Techniques on Visual Outcomes in Penetrating Keratoplasty EJO(MOC) 2021;3:161-167.

Table (2): Assessment of topographic astigmatism along the study duration in the two study groups

\begin{tabular}{|c|c|c|c|}
\hline Time & $\begin{array}{c}\text { Continous } \\
\text { suturing } \\
n=20\end{array}$ & $\begin{array}{c}\text { Interrupted } \\
\text { suturing } \\
n=20\end{array}$ & $\begin{array}{c}\text { Test of } \\
\text { significance }\end{array}$ \\
\hline 1 month postoperative & $5.49 \pm 1.37$ & $5.91 \pm 2.62$ & $\begin{array}{c}z=-0.643 \\
P=0.524\end{array}$ \\
\hline 3 months postoperative & $5.16 \pm 1.33$ & $5.69 \pm 2.46$ & $\begin{array}{c}z=-0.841 \\
P=0.406\end{array}$ \\
\hline 6 months postoperative & $4.83 \pm 1.29$ & $5.53 \pm 1.98$ & $\begin{array}{c}z=-1.324 \\
P=0.193\end{array}$ \\
\hline 1 year postoperative & $4.58 \pm 1.22$ & $4.53 \pm 1.83$ & $\begin{array}{l}z=0.102 \\
P=0.919\end{array}$ \\
\hline Overall significance & $\begin{array}{l}F=21.599 \\
P=\mathbf{0 . 0 0 1 *}\end{array}$ & $\begin{array}{l}F=30.761 P< \\
0.001 *\end{array}$ & \\
\hline
\end{tabular}

P: probability.

Continuous data expressed as mean $\pm \mathrm{SD}$

z: Mann Whitney U-test

$F$ : repeated measures $A N O V A$

*: significant value $<0.05$

The cases that received interrupted suturing needed more intervention as compared with the cases underwent continuous suturing with difference between both the study groups that proved to be significant statistically (table 3 ). In underwent readjustment and 1 case $(5 \%)$ at 6 months. In the interrupted group, at 1 month 8 cases $(40 \%)$ underwent readjustment, at 3 months 11 cases (55\%), 9 case (45\%) at 6 months and 3 cases 1 year $(15 \%)$.

the continuous suturing groups at 3 months 2 cases $(10 \%)$

Table (3): Cases which needed intervention in the form of selective suture removal (Interrupted) or suture readjustment (continuous)

\begin{tabular}{lccc}
\hline Time & $\begin{array}{c}\text { Continuous } \\
\text { suturing } \\
n=20\end{array}$ & $\begin{array}{c}\text { Interrupted } \\
\text { suturing } \\
n=20\end{array}$ & $\begin{array}{c}\text { Test of } \\
\text { significance }\end{array}$ \\
\hline 1 month postoperative & $0(0 \%)$ & $8(40 \%)$ & $\square<0.001^{*}$ \\
3 months postoperative & $2(10 \%)$ & $11(55 \%)$ & $\square 2=8.345$ \\
6 months postoperative & $1(5 \%)$ & $9(45 \%)$ & $P<0.001^{*}$ \\
1 year postoperative & $0(0 \%)$ & $3(15 \%)$ & $P<0.258$ \\
& & $\square 2=1.458$ \\
\hline
\end{tabular}

P: probability.

z: Mann Whitney U-test

*: significant value $<0.05$ 
Table (4): Assessment of BCVA along the study duration in the two study groups

\begin{tabular}{|c|c|c|c|}
\hline Time & $\begin{array}{c}\text { Continuous } \\
\text { suturing } \\
n=20\end{array}$ & $\begin{array}{c}\text { Interrupted } \\
\text { suturing } \\
n=20\end{array}$ & $\begin{array}{c}\text { Test of } \\
\text { significance }\end{array}$ \\
\hline Preoperative & $1.90 \pm 0.25$ & $1.86 \pm 0.33$ & $\begin{array}{l}t=0.477 \\
P=0.639\end{array}$ \\
\hline 1 month postoperative & $0.67 \pm 0.14$ & $0.66 \pm 0.14$ & $\begin{array}{l}t=0.245 \\
P=0.808\end{array}$ \\
\hline 3 months postoperative & $0.59 \pm 0.14$ & $0.61 \pm 0.11$ & $\begin{array}{c}t=-0.446 \\
P=0.658\end{array}$ \\
\hline 6 months postoperative & $0.51 \pm 0.14$ & $0.56 \pm 0.10$ & $\begin{array}{c}t=-1.101 \\
P=0.278\end{array}$ \\
\hline 1 year postoperative & $0.40 \pm 0.16$ & $0.37 \pm 0.15$ & $\begin{array}{l}z=0.659 \\
P=0.514\end{array}$ \\
\hline Overall significance & $\begin{array}{l}F=74.073 \\
P<\mathbf{0 . 0 0 1 *}\end{array}$ & $\begin{array}{l}F=44.326 \\
P<0.001 *\end{array}$ & \\
\hline
\end{tabular}

P: probability.

Continuous data expressed as mean $\pm \mathrm{SD}$

z: Mann Whitney U-test

$t$ : independent samples $t$-test $F$ : repeated measures ANOVA

*: significant value $<0.05$

Table (4) shows that there was no statistically significant difference in the mean VA in the cases within the two study groups Preoperative, at 1 month postoperative, at 3 months postoperative, at 6 months postoperative and at 1 year postoperative. There was a statistically significant improvement in the cases within the two study groups along the duration of follow up when compared to the preoperative value $(\mathrm{P}<0.001)$.

\section{Discussion}

The results of the study showed comparable improvement between the two techniques regarding the BCVA, refractive astigmatism and topographic astigmatism. The need for readjustment was higher in the cases that underwent interrupted suturing.

In the current study we decided to follow-up the cases for just one year and not for 18 months or 2 years like in other studies. This was to decrease the patient leak throughout the study and was based on the relative stability in results at 18 months and 2 years in the previous studies as concluded by Vinciguera et al., ${ }^{11}$.

Williams et al. evaluated 60 patients who underwent PK with different preoperative diagnoses and noted that $38 \%$ of patients had $5 \mathrm{D}$ or more astigmatism ${ }^{13}$. Similarly, in a recent study, the mean refractive astigmatism and topographic astigmatism were $4.85 \pm 1.04 \mathrm{D}$ and $5.24 \pm 1.08 \mathrm{D}$ respectively ${ }^{14}$.

Our results agreed with other studies in the literature as they reported that a wide range of post-keratoplasty astigmatic error was obtained with interrupted suture technique. The elevated levels of post-keratoplasty astigmatic error with interrupted sutures are usually in the early post-keratoplasty period prior to selective removal of tight sutures. Yet, the end result keratometric astigmatic value obtained by the end of rehabilitation is convenient, as concluded by various clinical studies $^{15,16}$.

This could be explained to be due to the uneven force distribution of the sutures and the lack of intraoperative keratometry use. The delayed influence of selective removal 
of tight sutures on the astigmatic error is because it must be delayed until 2 months postoperative and is no more than 1 suture at a time.

Suture adjustment is accepted as a safe postoperative procedure with a profound influence on astigmatic error with immediate results which are stable for as late as 3 years post adjustment ${ }^{17}$. Also, single continuous suture tension postkeratoplasty adjustment decreases post-keratoplasty astigmatic error even after sutures are out ${ }^{18}$.

In the current study, the cases that underwent interrupted suturing needed more intervention as compared with the cases that underwent continuous suturing with statistically significant difference between the two study groups. In the continuous suturing groups at 3 months 2 cases $(10 \%)$ underwent readjustment and 1 case $(5 \%)$ at 6 months. In the interrupted group, at 1 month 8 cases (40\%) underwent readjustment, at 3 months 11 cases (55\%), 9 case (45\%) at 6 months and 3 cases 1 year (15\%).

Vinciguerra et al. ${ }^{11}$ conducted a study which enrolled 165 eyes of 150 patients. Data from 108 (64.5\%) eyes of the first month follow up were supplied which reported that suture adjustment was done in $31.5 \%$ of patients (34/108).

Our results agreed with Karabatsas et al. (1998) who performed a randomized prospective study comparing single running \& interrupted technique. Single running group followed by postoperative suture tension adjustment showed nearly similar results to the interrupted group followed by selective removal of tight sutures ${ }^{19}$.

Our results disagreed with Vajpayee et al. (2001) who showed that Interrupted sutures produce more final postkeratoplasty astigmatic error than single continuous suture. He stated that the difference is generated by the different models of corneal tension distribution provided by both types, as the single running provides even distribution while the interrupted sutures distorts that distribution. In our study, although we partially agreed with the study in the early post-operative stage but in the final stage any uneven distribution was dealt with by selective suture removal which leaves corneas of even tension distribution comparable to that of continuous sutures ${ }^{20}$.

\section{Conclusion}

To conclude, there were no significant visual or refractive differences between patients operated with continuous \& interrupted suturing techniques. However, the continuous suturing revealed slight superiority as interrupted suturing needed more intervention. Although the selective suture removal is an outpatient and relatively simple procedure with minimal learning curve, but it may be done more than once in several follow-ups to achieve the desired outcome, so it is better avoided in patients whom sticking to follow-up is not guaranteed.

\section{Conflict of Interest}

Authors declare no conflicts of interest.

\section{Corresponding author}

Correspondence to: Ahmed Raouf

Email: ahmedraouf81@gmail.com

\section{Affiliations}

Ahmed Raouf, Department of Ophthalmology, Faculty of Medicine, Mansoura University, Egypt.

\section{Ethics declarations}

\section{Conflict of interest}

Ahmed Raouf, Sameh Saleh, Maha Othman, Eman El-Hifny, Ahmed Ismail, all authors have no conflicts of interest that are directly relevant to the content of this review.

Funding: No sources of funding were used to conduct this review.

Reviewer disclosures: No relevant financial or other relationships to disclose.

Declaration of interest: No financial affiliations or financial involvement with any organization or entity with a financial competing with the subject matter or materials discussed in the review.

\section{References:}

1. Javadi MA, Motlagh BF, Jafarinasab MR, Rabbanikhah Z, Anissian A, Souri H, Yazdani S. Outcomes of penetrating keratoplasty in keratoconus. Cornea. 2005;24(8):941-6.

2. Lim L, Pesudovs K, Coster DJ. Penetrating keratoplasty for keratoconus: visual outcome and success. Ophthalmology. 2000 Jun 1;107(6):1125-31.

3. Corbett M, Maycock N, Rosen E, O'Brart D. Keratoplasty. In Corneal Topography. Springer, Cham 2019;pp. 171187.

4. Feizi S, Zare M. Current approaches for management of postpenetrating keratoplasty astigmatism. Journal of Ophthalmology. 2011;2011. 
5. Goweida MB, Helaly HA. Influence of surgical factors on postoperative corneal refractive power and astigmatism after keratoplasty. Journal of the Egyptian Ophthalmological Society. 2014 Oct 1;107(4):253.

6. Dolorico AM, Tayyani R, Ong HV, Gaster RN. Short-term and long-term visual and astigmatic results of an opposing 10-0 nylon double running suture technique for penetrating keratoplasty. Journal of the American College of Surgeons. 2003 Dec 1;197(6):991-9.

7. Feizi S. Management of Post-Penetrating Keratoplasty Astigmatism. Astigmatism: Optics, Physiology and Management. 2012 Feb 29:135.

8. Kim SJ, Wee WR, Lee JH, Kim MK. The effect of different suturing techniques on astigmatism after penetrating keratoplasty. Journal of Korean medical science. 2008 Dec 1;23(6):1015-9.

9. Olson RJ, Pingree M, Ridges R, Lundergan ML, Alldredge Jr C, Clinch TE. Penetrating keratoplasty for keratoconus: a long-term review of results and complications. Journal of Cataract \& Refractive Surgery. 2000 Jul 1;26(7):987-91.

10. Spadea L, Cifariello F, Bianco G, Balestrazzi E. Long-term results of penetrating keratoplasty using a single or double running suture technique. Graefe's archive for clinical and experimental ophthalmology. 2002 May 1;240(5):415-9.

11. Vinciguerra P, Epstein D, Albè E, Spada F, Incarnato N, Orzalesi N, Rosetta P. Corneal topography-guided penetrating keratoplasty and suture adjustment: new approach for astigmatism control. Cornea. 2007 Jul 1;26(6):675-82.

12. Lee RM, Lam FC, Georgiou T, Paul B, Then KY, Mavrikakis I, Avadhanam VS, Liu CS. Suturing techniques and postoperative management in penetrating keratoplasty in the United Kingdom. Clinical Ophthalmology (Auckland, NZ). 2012;6:1335.

13. Williams KA, Ash JK, Pararajasegaram P, Harris S, Coster DJ. Long-term outcome after corneal transplantation: visual result and patient perception of success. Ophthalmology. 1991 May 1;98(5):651-7.

14. Raj A, Dhasmana R, Bahadur H. Suture related astigmatism after penetrating keratoplasty. Sudanese Journal of Ophthalmology. 2019 Jul 1;11(2):48.
15. Ramirez M, Hodge DO, Bourne WM. Keratometric results during the first year after keratoplasty: adjustable single running suture technique versus double running suture technique. Ophthalmic Surgery, Lasers and Imaging Retina. 2001 Sep 1;32(5):370-4.

16. Lee WB, Mannis MJ. Corneal suturing techniques. In Ophthalmic microsurgical suturing techniques 2007 (pp. 49-59). Springer, Berlin, Heidelberg.

17. Hirst LW, McCoombes JA, Reedy M. Postoperative suture manipulation for control of corneal graft astigmatism. Australian and New Zealand journal of ophthalmology. 1998 Aug;26(3):211-4.

18. McNeill JI, Aaen VJ. Long-term results of single continuous suture adjustment to reduce penetrating keratoplasty astigmatism. Cornea. 1999 Jan;18(1):19-24.

19. Karabatsas CH, Cook SD, Figueiredo FC, Diamond JP, Easty DL. Combined interrupted and continuous versus single continuous adjustable suturing in penetrating keratoplasty: a prospective, randomized study of induced astigmatism during the first postoperative year. Ophthalmology. 1998 Nov 1;105(11):1991-8.

20. Vajpayee RB, Sharma V, Sharma N, Panda A, Taylor HR. Evaluation of techniques of single continuous suturing in penetrating keratoplasty. British journal of ophthalmology. 2001 Feb 1;85(2):134-8. 